\title{
Preparation of divinyl esters by transvinylation between vinyl acetate and dicarboxylic acids
}

\author{
Imane Barbara, ${ }^{\text {a }}$ Marc Birot, ${ }^{a}$ Alexander Bismarck, ${ }^{b}$ and Hervé Deleuze ${ }^{\mathrm{a} *}$ \\ ${ }^{a}$ University of Bordeaux, Institut des Sciences Moléculaires, UMR-CNRS 5255, F-33405 \\ Talence, France \\ ${ }^{b}$ University of Vienna, Department of Material Chemistry, Polymer and Composite Engineering \\ (PaCE) group, A-1090 Wien, Austria \\ E-mail: herve.deleuze@u-bordeaux.fr
}

DOI: http://dx.doi.org/10.3998/ark.5550190.p009.410

\begin{abstract}
Transvinylation of aromatic and aliphatic diacids with vinyl acetate using several catalytic systems have been studied under conventional heating and microwave activation. In any case, a single addition of catalyst gave only low conversion into diester, due to a rapid deactivation of the catalysts, the best results being obtained with [pyridine $]_{2} \cdot \mathrm{Pd}(\mathrm{OAc})_{2}$. Successive additions of $\mathrm{Pd}(\mathrm{OAc})_{2}$ as catalyst gave better results with a $65 \%$ yield in isolated pure divinyl dodecanedioate after the successive addition of three catalyst portions. Kinetics and catalytic mechanism considerations helped to discuss these results.
\end{abstract}

Keywords: Transvinylation, divinyl esters, palladium catalyst, microwave activation

\section{Introduction}

Divinyl esters have found applications as co-reagents in acyl transfer reactions: the tautomerization of the vinyl alcohol formed into acetaldehyde displaces the reaction equilibrium towards the formation of the polymer. ${ }^{1}$ Therefore, divinyl esters are very attractive monomers for the synthesis of polyesters in mild reaction conditions, using either chemical or enzymatic catalysts (Scheme 1). ${ }^{2}$ 


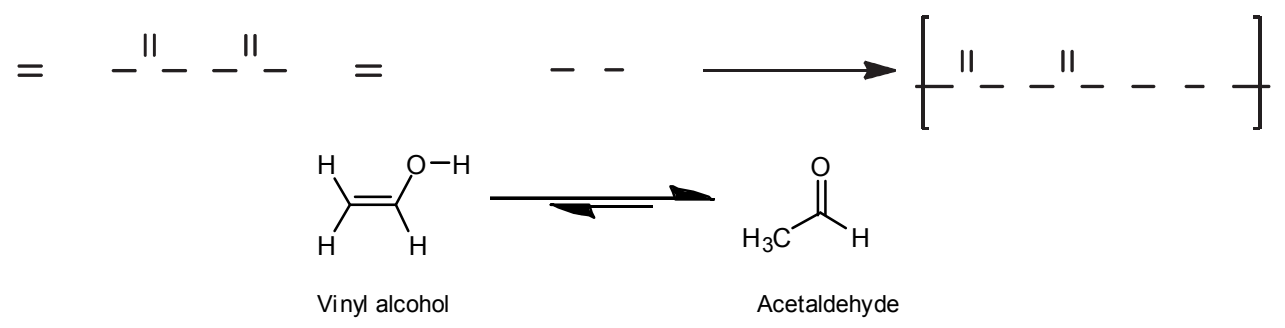

Scheme 1. Irreversible polyester preparation using divinyl esters monomers.

Divinyl esters are also very useful in the preparation of low toxicity biomaterials by photopolymerization. ${ }^{3}$ However, their efficient preparation remains a challenge. Only 1,10divinyl adipate, prepared from acetylene, is commercially available, ${ }^{4}$ while few examples of synthesis of divinyl esters are described in the literature, with generally low yields. ${ }^{5}$ This situation limits the development of the use of divinyl esters in polymer chemistry. Therefore, it would be of interest to develop a general laboratory-scale, efficient method to synthesize aliphatic and aromatic divinyl esters.

At the laboratory, monovinyl esters are generally prepared by a transvinylation reaction between a carboxylic acid and vinyl acetate. ${ }^{6}$ The use of $\mathrm{Hg}(\mathrm{II})$ salts as catalyst is a well established method that gives rather satisfactory results in most cases. ${ }^{7}$ However, the high toxicity of mercury and its derivatives is now well established, ${ }^{8}$ and numerous attempts such as the Minamata Convention ${ }^{9}$ are engaged to banish as much as possible the extraction and uses of mercury. In the case of the transvinylation reaction, substitutes like Pd(II) salts have been proposed as substitute. ${ }^{10,11}$ Palladium salts are less toxic than mercury ones and show a good transvinylation activity, but they suffer from reduction into metallic palladium, which leads to a rapid loss of activity, requiring the use of rather large amounts of costly reagents. In order to overcome this behavior, ruthenium complexes were proposed as alternative. ${ }^{12} \mathrm{~A}$ reaction mechanism of transvinylation promoted by ruthenium catalyst has been proposed. More recently, iridium complexes were also suggested. ${ }^{13}$

Transvinylation reaction between a carboxylic acid and vinyl acetate is known to be a reversible reaction whose equilibrium constant is close to unity. ${ }^{4}$ The by-product of the reaction - acetic acid - is difficult to remove from the media without extracting vinyl acetate at the same time $\left(E b_{\text {acetic acid }}=118{ }^{\circ} \mathrm{C}, E b_{\text {vinyl acetate }}=72.7^{\circ} \mathrm{C}\right)$. Therefore, vinyl acetate is generally used in large excess in order to displace the equilibrium.

Microwave activation has become a widely used methodology in organic chemistry. ${ }^{14}$ Microwave heating has been used in the synthesis of vinyl esters from carboxylic acids and alkynes, ${ }^{15}$ indicating a considerable acceleration of the reactions. However, the application of microwaves to transvinylation reactions does not appear to have been published. Therefore, it seemed interesting to test this method of heating in our work. 
In the course of our research on green polyesters preparation, we were interested in the development of an efficient preparation of aromatic and aliphatic divinyl esters. Therefore, we decided to investigate the activity of different catalytic systems previously reported for the preparation of monovinyl esters for the synthesis of divinyl aromatic and aliphatic esters. Conventional heating and microwave activation were both investigated and results compared.

\section{Results and Discussion}

\section{Research of optimal conditions}

One-shot catalyst addition. In a first time, isophthalic acid (benzene-1,3-dicarboxylic acid) was chosen as a transvinylation reaction model. The preparation of divinyl isophthalate from isophthalic acid by transvinylation is a two-step reversible system (Scheme 2).

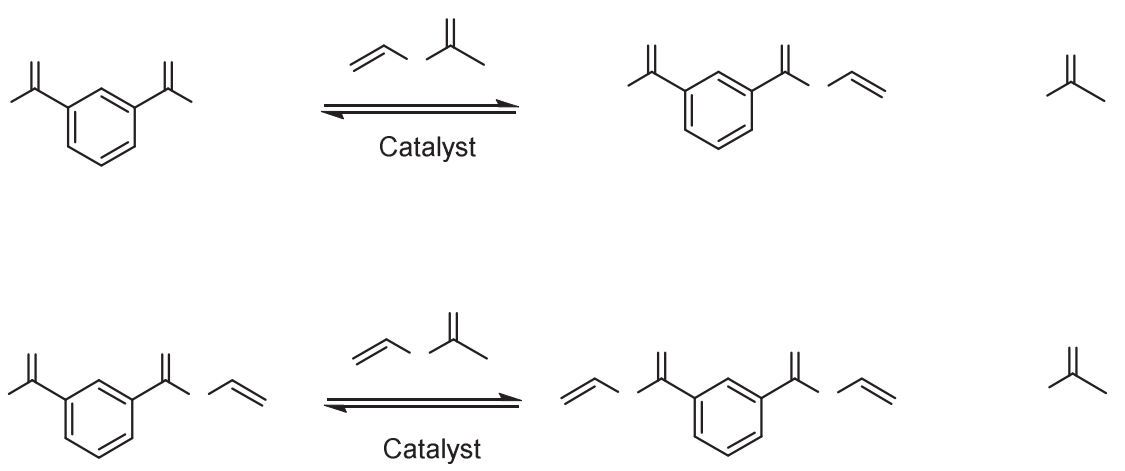

Scheme 2. Preparation of divinyl isophthalate from isophthalic acid.

Several catalytic systems reported in the literature to be efficient for the preparation of monovinyl esters by transvinylation were tested in the preparation of divinyl isophthalate from isophthalic acid. Vinyl acetate was used in a large excess to displace the equilibrium toward the formation of divinyl esters. Conventional heating as well as microwave activation have been investigated. The different transvinylation attempts performed on isophthalic acid are reported in Tables 1 and 2.

Transvinylation using mercury salts under conventional heating. The use of mercury acetate to catalyze the transvinylation between vinyl acetate and isophthalic acid (ratio 10/1) gave only the monovinyl intermediate with a moderate yield of $33 \%$ (Table 1, entry 1 ).

Transvinylation using palladium acetate. Under conventional thermal conditions, conversion of isophthalic acid using an excess of vinyl acetate (10/1) reached $45 \%$ of monovinyl isophthalate and about $10 \%$ of the divinyl ester (Table 1, entry 2). This result can be related to 
the preparation of vinyl benzoate from benzoic acid using a similar catalytic system that gives a yield of $43 \% .{ }^{10}$ An increase of the temperature from $60{ }^{\circ} \mathrm{C}$ to $100{ }^{\circ} \mathrm{C}$ still lowered the yield to $37 \%$ (Table 1, entry 3). This behavior confirms the sensitivity of $\operatorname{Pd}(\mathrm{OAc})_{2}$ to the temperature, due to its reduction into inactive metallic palladium, as already reported. ${ }^{3}$

Using microwave activation, the total conversion of isophthalic acid was increased but without a real impact on divinyl isophthalate production: the monovinyl ester accumulated in the reaction medium (Table 1, entry 4). However, the reaction time reduced from $48 \mathrm{~h}$ to $2 \mathrm{~h}$ (Table 1, entries 2 and 4). The use of an even larger excess of vinyl acetate (30/1) did not change significantly the situation (Table 1, entry 5). Furthermore, no reaction was observed in the absence of solvent (Table 1, entry 6), or with encapsulated palladium ${ }^{16}$ as catalyst, used under the same reaction conditions as $\mathrm{Pd}(\mathrm{OAc})_{2}$ under microwave irradiation (Table 1, entry 7).

The complexation of $\mathrm{Pd}(\mathrm{OAc})_{2}$ by nitrogen bidentate ligands was reported to enhance the stability of the catalysts during the transvinylation reaction. ${ }^{17}$ Therefore, $[2,2$ '-bipyridyl $] \cdot \mathrm{Pd}(\mathrm{OAc})_{2}$ and $[\text { pyridine }]_{2} \cdot \operatorname{Pd}(\mathrm{OAc})_{2}$ complexes were synthesized and tested as catalysts. [2,2'-bipyridyl] $\mathrm{Pd}(\mathrm{OAc})_{2}$ was tested first under conventional heating and microwaves activation (Table 1, entries 8 and 9). The catalyst was found to be more stable than $\mathrm{Pd}(\mathrm{OAc})_{2}$ : no metallic palladium deposition was observed on the reactor glass. However, diacid conversion was low with no detection of divinyl ester in both cases. In that case, conventional heating and microwaves gave similar results, however in shorter time for the latter.

In contrary, when $[\text { pyridine }]_{2} \cdot \mathrm{Pd}(\mathrm{OAc})_{2}$ was used as catalyst (Table 1 , entry 10$), 95 \%$ of conversion of the diacid was obtained after $48 \mathrm{~h}$ of reaction at $60{ }^{\circ} \mathrm{C}$, with a $2: 1$ monovinyl ester/divinyl ester molar ratio.

The conversion of a symmetric diacid into its divinyl ester through a mono vinyl ester intermediate can be considered as a two consecutive reactions system, each step being of a pseudo-first order, considering the large excess of vinyl acetate involved. This kinetic system can be analytically resolved. ${ }^{18}$ The evolution of the concentrations found in the different experiments performed shows an accumulation of monovinyl ester before its slow conversion into the final divinyl ester product. This behavior can be attributed to a first step apparent reaction rate much higher than the second step apparent reaction rate $\left(k_{1 \text { app }}>>k_{2 \text { app }}\right)$. In the case of the use of Palladium catalysts, the reaction proceeds via the formation of a $\pi$-complex between Pd-complex and vinyl acetate monomer, followed by the nucleophilic attack of the carboxylic acid to give a palladium $\sigma$-complex with production of acetic acid as by-product. This $\sigma$-complex then undergoes $\beta$-acetate elimination to give Pd-complex and vinyl ester as a product. ${ }^{19}$ Therefore, it can be postulated that the decomposition of the Pd- $\sigma$-complex formed with the monovinyl ester intermediate is the limiting reaction step preventing the formation of the expected divinyl ester. The results obtained in this work confirm the low stability of palladium-based catalyst in the transvinylation reaction. Therefore, several newly proposed catalysts for this reaction were tested in order to avoid this deactivation. 
Transvinylation using ruthenium catalyst in autoclave. Triruthenium dodecacarbonyl was used for the transvinylation reaction of vinyl acetate and isophthalic acid (ratio 10/1). The reaction was performed in a pressure reactor at high temperature $\left(150{ }^{\circ} \mathrm{C}\right)$. The performance of the catalyst was compared in the presence or absence of solvent (DMF) (Table 1, entries 11 and 12). No vinyl esters products were obtained for the reaction in solvent, and a degradation of the initial diacid was observed. In the absence of solvent, the use of triruthenium dodecacarbonyl as catalyst gave low conversion, similar to that observed with $\operatorname{Pd}(\mathrm{OAc})_{2}$ (compare Table 1, entries 3 and 12).

Transvinylation using iridium catalyst. Transvinylation reaction using chloro(1,5cyclooctadiene)iridium(I) dimer have been performed under conventional heating conditions. Conversion of isophthalic acid using an excess of vinyl acetate (10/1) allowed the formation of $32 \%$ of monovinyl isophthalate with no apparent formation of divinyl ester (Table 1, entry 13). These results indicate that ruthenium and iridium-based catalysts do not significantly improve the transvinylation reaction efficiency in cases where isophthalic acid is involved.

Table 1. Preparation of divinyl isophthalate from isophthalic acid by transvinylation in DMF

\begin{tabular}{|c|c|c|c|c|c|c|c|c|}
\hline \multirow[b]{2}{*}{$\#$} & \multirow[b]{2}{*}{$\begin{array}{l}\text { Catalyst } \\
(5 \% \mathrm{~mol})\end{array}$} & \multirow[b]{2}{*}{ Conditions $^{\mathrm{a}}$} & \multirow{2}{*}{$\begin{array}{c}\text { Vinyl } \\
\text { acetate/ } \\
\text { diacid } \\
\text { molar ratio }\end{array}$} & \multirow[b]{2}{*}{$\begin{array}{c}\mathrm{T} \\
\left({ }^{\circ} \mathrm{C}\right)\end{array}$} & \multirow[b]{2}{*}{$\begin{array}{l}\text { Reaction } \\
\text { time (h) }\end{array}$} & \multicolumn{3}{|c|}{ Final molar distribution $(\%)^{b}$} \\
\hline & & & & & & $\begin{array}{c}\text { Isophthalic } \\
\text { acid }\end{array}$ & $\begin{array}{l}\text { Monovinyl } \\
\text { isophthalate }\end{array}$ & $\begin{array}{c}\text { Divinyl } \\
\text { isophthalate }\end{array}$ \\
\hline 1 & $\mathrm{Hg}(\mathrm{OAc})_{2}$ & Conventional & $10 / 1$ & 60 & 4 & 67 & 33 & 0 \\
\hline 2 & $\mathrm{Pd}(\mathrm{OAc})_{2}$ & Conventional & $10 / 1$ & 60 & 48 & 46 & 45 & 9 \\
\hline 3 & $\mathrm{Pd}(\mathrm{OAc})_{2}$ & Conventional & $10 / 1$ & 100 & 48 & 63 & 37 & 0 \\
\hline 4 & $\mathrm{Pd}(\mathrm{OAc})_{2}$ & $\mathrm{MW}^{\mathrm{c}}$ & $10 / 1$ & 60 & 2 & 18 & 68 & 14 \\
\hline 5 & $\mathrm{Pd}(\mathrm{OAc})_{2}$ & $\mathrm{MW}^{\mathrm{c}}$ & $30 / 1$ & 60 & 2 & 11 & 74 & 15 \\
\hline $6^{\mathrm{d}}$ & $\mathrm{Pd}(\mathrm{OAc})_{2}$ & $\mathrm{MW}^{\mathrm{c}}$ & $30 / 1$ & 60 & 2 & 100 & 0 & 0 \\
\hline 7 & Pd Encat ${ }^{\circledR}$ & $\mathrm{MW}^{\mathrm{c}}$ & $10 / 1$ & 60 & 2 & 100 & 0 & 0 \\
\hline 8 & {$\left[2,2^{\prime}\right.$-bipyridyl $] \cdot \mathrm{Pd}(\mathrm{OAc})_{2}$} & Conventional & $10 / 1$ & 60 & 48 & 81 & 19 & 0 \\
\hline 9 & {$\left[2,2^{\prime}\right.$-bipyridyl $] \cdot \operatorname{Pd}(\mathrm{OAc})_{2}$} & $\mathrm{MW}^{\mathrm{c}}$ & $10 / 1$ & 60 & 5 & 84 & 16 & 0 \\
\hline 10 & {$[\text { pyridine }]_{2} \cdot \operatorname{Pd}(\mathrm{OAc})_{2}$} & Conventional & $10 / 1$ & 60 & 48 & 5 & 65 & 30 \\
\hline 11 & $\mathrm{Ru}_{3}(\mathrm{CO})_{12}$ & Autoclave & $10 / 1$ & 150 & 3 & 100 & 0 & 0 \\
\hline $12^{\mathrm{d}}$ & $\mathrm{Ru}_{3}(\mathrm{CO})_{12}$ & Autoclave & $10 / 1$ & 150 & 3 & 63 & 30 & 7 \\
\hline 13 & $\mathrm{C}_{16} \mathrm{H}_{24} \mathrm{Cl}_{2} \mathrm{Ir}_{2}$ & Conventional & $10 / 1$ & 100 & 24 & 68 & 32 & 0 \\
\hline
\end{tabular}

${ }^{\mathrm{a}}$ See text for details, ${ }^{\mathrm{b}}$ determined by ${ }^{1} \mathrm{H}$ NMR, ${ }^{\mathrm{c}}$ microwave activation, ${ }^{\mathrm{d}}$ solvent free reaction. 


\section{Successive catalyst addition}

The various attempts of transvinylation of isophthalic acid with vinyl acetate carried out using a one-shot catalyst addition at the start of the reaction show that, whatever the catalyst used, the conversion is incomplete, mainly due to a rapid catalyst deactivation. Therefore, it may be advantageous to operate by successive additions of catalyst in order to keep a sufficient amount of active catalyst during the course of the reaction.

Microwave-assisted transvinylation with successive additions of palladium acetate. Transvinylation of isophthalic acid with vinyl acetate catalyzed by $\mathrm{Pd}(\mathrm{OAc})_{2}$ was then conducted under microwaves with successive addition of fresh catalyst portions in order to improve the displacement of the reaction toward the formation of divinyl isophthalate by limiting the effect of the catalyst deactivation. After the first run, the remaining isophthalic acid $(20 \%$ of initial amount), the formed acetic acid and most of the vinyl acetate was removed and the unseparated monovinyl / divinyl isophthalate mixture put again into reaction with fresh amounts of catalyst (5\% mol relative to initial diacid amount) and vinyl acetate (10 eq. relative to initial diacid). This was repeated twice (Table 2).

Table 2. Evolution of the monovinyl isophthalate/divinyl isophthalate ratio with successive catalyst addition

\begin{tabular}{ccccccc}
\hline$\#$ & Catalyst & Conditions & Experiment & $\mathbf{T}^{\circ} \mathbf{C}$ & $\begin{array}{c}\text { Reaction } \\
\text { time (h) }\end{array}$ & $\begin{array}{c}\text { Monovinyl } \\
\text { isophthalate/divinyl } \\
\text { isophthalate molar ratio }\end{array}$ \\
\hline $\mathbf{1 4}$ & & & $1^{\text {st }}$ & 60 & 2 & $81 / 19$ \\
$\mathbf{1 5}$ & $\mathrm{Pd}(\mathrm{OAc})_{2}$ & $\mathrm{MW}$ & $2^{\text {nd }}$ & 60 & 2 & $52 / 48$ \\
$\mathbf{1 6}$ & & $3^{\text {rd }}$ & 60 & 2 & $26 / 74$ \\
\hline
\end{tabular}

${ }^{\mathrm{a}}$ Determined by ${ }^{1} \mathrm{H} \mathrm{NMR}$;

Results obtained indicate that the monovinyl isophthalate/divinyl isophthalate molar ratio of about 4:1 achieved in the first experiment (Table 2, entry 14) can be displaced to almost 1:1 with a first addition of fresh catalyst (Table 2, entry 15) and finally to a 1:3 value after a second addition (Table 2, entry 16). Finally, the molar percent distribution obtained after the third run is isophthalic acid: $20 \%$, monovinyl isophthalate: $21 \%$ and divinyl isophthalate: $60 \%$. This procedure appears therefore to be an efficient way to improve the yield of divinyl ester.

\section{Preparative applications}

One-shot catalyst addition. A preparative experiment was performed starting from a larger amount of isophthalic acid $(0.1 \mathrm{~mol})$, otherwise using the best experimental conditions obtained for the preparation of divinyl isophthalate i.e.: catalyst [pyridine $]_{2} \cdot \mathrm{Pd}(\mathrm{OAc})_{2}$, vinyl acetate $(10$ eq.), $60{ }^{\circ} \mathrm{C}, 48 \mathrm{~h}$ in DMF (Table 1, entry 10). Isophthalic acid, monovinyl isophthalate and 
divinyl isophthalate were then separated by precipitation and distillation under vacuum. The molar percent distribution obtained is: isophthalic acid: $5 \%$, monovinyl isophthalate: $65 \%$ and divinyl isophthalate: $30 \%$. The isolated yield in divinyl isophthalate was $30 \%$.

Successive catalyst addition. In order to confirm the interest of the successive additions of catalyst in the preparation of divinyl esters, this procedure was conducted on an aliphatic diacid : dodecanedioic acid. The procedure was the same as previously reported for isophthalic acid but on a larger scale (Table 3).

The dodecanedioic acid remaining after the first run $(18 \%$ of the initial amount) is removed by selective precipitation before the second run. The monovinyl /divinyl dodecanedioate molar ratio of 3:7 reached in the first experiment (Table 3, entry 17) can be displaced to more than 1:6 with a first addition of fresh catalyst (Table 3 , entry 18) and to a 1:9 value after a second addition (Table 3, entry 19) indicating an almost complete conversion. Finally, the molar percent distribution obtained after the third run is dodecanedioic acid: $18 \%$, monovinyl dodecanedioate: $10 \%$ and divinyl dodecanedioate $72 \%$.

The procedure of successive addition of catalyst fractions, completed by a selective removal of the unreacted diacid in the first run, allows to obtain divinyl dodecanedioate with a conversion of $72 \%$ from the diacid involved and a purity of $88 \%$; the remaining impurity being the monovinyl ester intermediate. Purification by column chromatography allows to obtain divinyl dodecanedioate with a $100 \%$ purity and a yield of $65 \%$ from the starting diacid. This result compares positively with the literature. ${ }^{20}$

Table 3. Evolution of the monovinyl/divinyl dodecanedioate ratio with catalyst addition

\begin{tabular}{ccccccc}
\hline$\#$ & Catalyst $^{\mathbf{a}}$ & Conditions & Experiment & $\begin{array}{c}\mathbf{T} \\
{ }^{\circ} \mathbf{C}\end{array}$ & $\begin{array}{c}\text { Reaction } \\
\text { time (h) }\end{array}$ & $\begin{array}{c}\text { monovinyl ester /divinyl } \\
\text { dodecanedioate molar ratio }^{\mathbf{b}}\end{array}$ \\
\hline $\mathbf{1 7}$ & & & $1^{\text {st }}$ & 60 & 2 & $30 / 70$ \\
$\mathbf{1 8}$ & $\mathrm{Pd}^{\mathrm{O}(\mathrm{OAc})_{2}}$ & $\mathrm{NW}$ & $2^{\text {nd }}$ & 60 & 2 & $14 / 86$ \\
$\mathbf{1 9}$ & & & $3^{\text {rd }}$ & 60 & 2 & $12 / 88$ \\
\hline
\end{tabular}

${ }^{\mathrm{a}}$ Catalyst amount: $5 \%$ mol relative to diacid initially involved, ${ }^{\mathrm{b}}$ determined by ${ }^{1} \mathrm{H} \mathrm{NMR}$.

\section{Conclusions}

In this study, several catalysts were tested in the transvinylation reaction of isophthalic acid with vinyl acetate. Conventional heating and microwave activation were both investigated. Pd(II) salts were found to be the most efficient catalysts. However, the major problem of palladium catalysts is their thermal instability. Therefore, palladium catalysts stability was enhanced by using $\operatorname{Pd}(\mathrm{II})$ complexes. The presence of polar solvent such as DMF appears to be required for the reaction to 
proceed. Recently proposed catalysts such as ruthenium and iridium complexes do not give substantially improved results in our hands.

The best result obtained using the one-shot catalyst addition in the transvinylation reaction of isophthalic acid with vinyl acetate was obtained with [pyridine $]_{2} \cdot \operatorname{Pd}(\mathrm{OAc})_{2}$ as catalyst giving an almost complete diacid conversion with an isolated yield in divinyl ester of $30 \%$.

The use of successive additions of palladium acetate to the reaction medium is another way to obtain a satisfactory conversion of a symmetric diacid, either aromatic or aliphatic, into its divinyl derivative through transvinylation with vinyl acetate. Indeed, divinyl dodecanedioate can be obtained in about $65 \%$ yield and $100 \%$ purity from the corresponding diacid by using three successive additions of $\mathrm{Pd}(\mathrm{OAc})_{2}$.

The use of microwaves activation accelerates significantly the reaction, thus reducing the deactivation of the catalyst.

\section{Experimental Section}

General. Triruthenium dodecacarbonyl, chloro(1,5-cyclooctadiene)iridium(I) dimer, were purchased from TCI. Mercury(II) acetate was purchased from Avocado. Isophthalic acid, dodecanedioic acid, vinyl acetate, $p$-toluene sulfonic acid, $\mathrm{CH}_{3} \mathrm{COOK}, \mathrm{Pd}(\mathrm{OAc})_{2}, 2$,2'-bipyridyl and pyridine were purchased from Sigma Aldrich and used as received. Deuterated solvents were purchased from Euriso-Top (Saint-Aubin, France). ${ }^{1} \mathrm{H}$ NMR spectra were recorded at $300 \mathrm{MHz}$. ${ }^{13} \mathrm{C}$ NMR spectra were recorded at $75 \mathrm{MHz}$. The elemental analyses were realized at the Institut des Sciences Analytiques (Villeurbanne, France). Microwave experiments: A single-mode microwave synthesizer (Start platform, Milestone, Inc., Rockford, IL) was used. This apparatus allows controlling simultaneously the temperature, the irradiation power, and the stirring speed.

\section{Palladium complexes preparation ${ }^{21}$}

[2,2'-Bipyridyl]·Pd(OAc) $)_{2}$. $\operatorname{Pd}(\mathrm{OAc})_{2}$ (1 eq.) and 2,2'-bipyridyl (1.5 eq.) were dissolved in acetonitrile (total molar concentration $0.2 \mathrm{~mol} \cdot \mathrm{L}^{-1}$ ). The mixture was refluxed for $4 \mathrm{~h}$. After cooling to room temperature the yellow complex obtained was isolated by filtration, washed twice with pentane and then dried $(Y=70 \%)$. Elemental analysis (\% mass). Found: $\mathrm{C}(50.23), \mathrm{H}$ (3.72), N (6.41), Pd (24.62); Calculated: C (50.42), H (3.29), N (6.53), O (14.92), Pd (24.82).

[Pyridine $]_{2} \cdot \mathbf{P d}(\mathbf{O A c})_{2} \cdot \operatorname{Pd}(\mathrm{OAc})_{2}$ (1 eq.) and pyridine (2.5 eq.) were dissolved in a mixture of diethyl ether and toluene $(1: 3)$ (total molar concentration $0.4 \mathrm{~mol} \cdot \mathrm{L}^{-1}$ ). The mixture was stirred for $4 \mathrm{~h}$ at room temperature. The light yellow complex obtained was isolated by filtration, washed twice with pentane and then $\operatorname{dried}(Y=75 \%)$.

Elemental analysis (\% mass). Found: C (50.61), H (4.16), N (6.42), Pd (24.11); Calculated: (C 50.19), H (3.74), N (6.50), O (14.86), Pd (24.72). 


\section{Analytical experiments on isophthalic acid}

Transvinylation reactions using $\mathbf{H g}(\mathrm{OAc})_{2}$ catalyst under conventional heating. Isophthalic acid (1.66 g, $0.01 \mathrm{~mol}, 1$ eq.) and vinyl acetate ( $8.6 \mathrm{~g}, 0.1 \mathrm{~mol}, 10$ eq.) were dissolved in DMF $(10 \mathrm{~mL})$ and the mixture was heated at $45^{\circ} \mathrm{C} . \mathrm{Hg}(\mathrm{OAc})_{2}\left(0.159 \mathrm{~g}, 5 \cdot 10^{-4} \mathrm{~mol}, 0.05\right.$ eq. $)$ and sulfuric acid $\left(0.05 \mathrm{~g}, 5 \cdot 10^{-4}, 0.05\right.$ eq. $)$ were added and the mixture was stirred at $60{ }^{\circ} \mathrm{C}$ for $4 \mathrm{~h}$. The reaction was stopped by adding $\mathrm{CH}_{3} \mathrm{COOK}\left(0.098 \mathrm{~g}, 10^{-3}\right.$ mol, 0.1 eq. $)$ and water $(10 \mathrm{~mL})$. The aqueous layer was extracted three times with dichloromethane $(3 \times 20 \mathrm{~mL})$. The organic layers were combined and washed with brine, dried over anhydrous $\mathrm{MgSO}_{4}$, filtered and concentrated. Mixture composition was analyzed by ${ }^{1} \mathrm{H}$ NMR.

\section{Transvinylation using Pd complexes catalysts under conventional heating}

With Pd(OAc)2. Isophthalic acid (1.66 g, $0.01 \mathrm{~mol}, 1$ eq.), vinyl acetate ( $8.6 \mathrm{~g}, 0.1 \mathrm{~mol}, 10$ eq.), $p$-toluene sulfonic acid $\left(0.172 \mathrm{~g}, 10^{-3} \mathrm{~mol}, 0.1\right.$ eq. $)$ and $\mathrm{Pd}(\mathrm{OAc})_{2}\left(0.112 \mathrm{~g}, 5 \cdot 10^{-4} \mathrm{~mol}, 0.05 \mathrm{eq}.\right)$ were dissolved in anhydrous DMF $(10 \mathrm{~mL})$. The mixture was stirred and heated at $60{ }^{\circ} \mathrm{C}$ for $48 \mathrm{~h}$ under $\mathrm{N}_{2}$. The reaction was stopped by adding $\mathrm{CH}_{3} \mathrm{COOK}\left(0.098 \mathrm{~g}, 10^{-3} \mathrm{~mol}, 0.1 \mathrm{eq}\right.$. $)$ and water $(10 \mathrm{~mL})$. The aqueous layer was extracted three times with dichloromethane $(3 \times 20 \mathrm{~mL})$. The organic layers were combined and washed with brine, dried over anhydrous $\mathrm{MgSO}_{4}$, filtered and concentrated. Mixture composition was analyzed by ${ }^{1} \mathrm{H}$ NMR.

With [2,2'-bipyridyl] $P$ Pd(OAc) 2 . Isophthalic acid (1.66 g, $0.01 \mathrm{~mol}, 1 \mathrm{eq}$.), vinyl acetate (8.6 g, 0.1 mol, 10 eq.), $p$-toluene sulfonic acid $\left(0.172 \mathrm{~g}, 10^{-3} \mathrm{~mol}, 0.1\right.$ eq.) and [2,2'bipyridyl $] \cdot \mathrm{Pd}(\mathrm{OAc})_{2}\left(0.192 \mathrm{~g}, 5 \cdot 10^{-4} \mathrm{~mol}, 0.05\right.$ eq. $)$ were dissolved in anhydrous DMF $(10 \mathrm{~mL})$. The mixture was stirred and heated at $60{ }^{\circ} \mathrm{C}$ for $48 \mathrm{~h}$ under $\mathrm{N}_{2}$. The reaction was stopped by adding $\mathrm{CH}_{3} \mathrm{COOK}\left(0.098 \mathrm{~g}, 10^{-3} \mathrm{~mol}, 0.1\right.$ eq.) and water $(10 \mathrm{~mL})$. The aqueous layer was extracted three times with dichloromethane $(3 \times 20 \mathrm{~mL})$. The organic layers were combined and washed with brine, dried over anhydrous $\mathrm{MgSO}_{4}$, filtered and concentrated. Mixture composition was analyzed by ${ }^{1} \mathrm{H}$ NMR.

With [pyridine] ${ }_{2} \cdot \mathbf{P d}(\mathbf{O A c})_{2}$. Isophthalic acid (1.66 g, $0.01 \mathrm{~mol}, 1$ eq.), vinyl acetate $(8.6 \mathrm{~g}, 0.1$ mol, 10 eq. $), p$-toluene sulfonic acid $\left(0.172 \mathrm{~g}, 10^{-3} \mathrm{~mol}, 0.1\right.$ eq. $)$ and [pyridine] $2 . \operatorname{Pd}(\mathrm{OAc})_{2}(0.194$ $\mathrm{g}, 5 \cdot 10^{-4} \mathrm{~mol}, 0.05$ eq. $)$ were dissolved in anhydrous DMF $(10 \mathrm{~mL})$. The mixture was stirred and heated at $60{ }^{\circ} \mathrm{C}$ under $\mathrm{N}_{2}$ for $48 \mathrm{~h}$. Reaction was stopped by adding $\mathrm{CH}_{3} \mathrm{COOK}\left(0.098 \mathrm{~g}, 10^{-3}\right.$ mol, 0.1 eq.) and water $(10 \mathrm{~mL})$. The aqueous layer was extracted three times with dichloromethane $(3 \times 20 \mathrm{~mL})$. The organic layers were combined and washed with brine, dried over anhydrous $\mathrm{MgSO}_{4}$, filtered and concentrated. Mixture composition was analyzed by ${ }^{1} \mathrm{H}$ NMR.

Microwave-assisted transvinylation using Pd complexes catalysts. The same procedure as for conventional heating experiments was followed. The reaction mixture was stirred in a microwave reactor for $2 \mathrm{~h}-5 \mathrm{~h}$ at $60{ }^{\circ} \mathrm{C}$. Reaction was stopped by adding $\mathrm{CH}_{3} \mathrm{COOK}(0.1$ eq.) and water (10 $\mathrm{mL}$ ). The aqueous layer was extracted four times with dichloromethane. The organic layers were 
combined and washed with brine, dried over anhydrous $\mathrm{MgSO}_{4}$, filtered and concentrated. Mixture composition was analyzed by ${ }^{1} \mathrm{H}$ NMR.

\section{Microwave-assisted transvinylation using successive addition of $\operatorname{Pd}(\mathrm{OAc})_{2}$ portions}

First run. Isophthalic acid (1.66 g, $0.01 \mathrm{~mol}, 1$ eq.), vinyl acetate ( $8.6 \mathrm{~g}, 0.1 \mathrm{~mol}, 10 \mathrm{eq}.), p$ toluene sulfonic acid $\left(0.172 \mathrm{~g}, 10^{-3} \mathrm{~mol}, 0.1\right.$ eq. $)$ and $\mathrm{Pd}(\mathrm{OAc})_{2}\left(0.112 \mathrm{~g}, 5 \cdot 10^{-4} \mathrm{~mol}, 0.05\right.$ eq. $)$ were dissolved in anhydrous DMF $(10 \mathrm{~mL})$. The reaction mixture was stirred in a microwave reactor for $2 \mathrm{~h}$ at $60{ }^{\circ} \mathrm{C}$. The reaction was stopped by adding $\mathrm{CH}_{3} \mathrm{COOK}\left(0.098 \mathrm{~g}, 10^{-3} \mathrm{~mol}, 0.1\right.$ eq.) and water $(10 \mathrm{~mL})$. Diethyl ether $(20 \mathrm{~mL})$ was added and the mixture triturated to allow precipitation of the unreacted isophthalic acid. The aqueous layer was extracted three times with dichloromethane $(3 \times 20 \mathrm{~mL})$. The organic layers were combined and washed with brine, dried over anhydrous $\mathrm{MgSO}_{4}$, filtered and concentrated. Mixture composition was analyzed by ${ }^{1} \mathrm{H}$ NMR.

Further runs. The concentrate collected from the previous run was added with a fresh mixture of vinyl acetate $(8.6 \mathrm{~g}, 0.1 \mathrm{~mol}), p$-toluene sulfonic acid $\left(0.172 \mathrm{~g}, 10^{-3} \mathrm{~mol}\right)$ and $\mathrm{Pd}(\mathrm{OAc})_{2}(0.112$ $\left.\mathrm{g}, 5 \cdot 10^{-4} \mathrm{~mol}\right)$ dissolved in anhydrous DMF $(10 \mathrm{~mL})$. Reactions and work-up were as for first run. Mixture composition was analyzed by ${ }^{1} \mathrm{H}$ NMR.

Transvinylation reactions using triruthenium dodecacarbonyl catalyst. Isophthalic acid ( $1.66 \mathrm{~g}, 0.01 \mathrm{~mol}, 1 \mathrm{eq}$.$) , vinyl acetate (8.6 \mathrm{~g}, 0.1 \mathrm{~mol}, 10$ eq. $)$ and triruthenium dodecacarbonyl $\left(0.320 \mathrm{~g}, 5 \cdot 10^{-4} \mathrm{~mol}, 0.05\right.$ eq. $)$ were dissolved in anhydrous DMF and the solution was introduced into a pressure stainless steel reactor. The reaction mixture was stirred for $3 \mathrm{~h}$ at 150 ${ }^{\circ} \mathrm{C}$. The vessel was cooled and water added $(10 \mathrm{~mL})$. The aqueous layer was extracted three times with dichloromethane $(3 \times 20 \mathrm{~mL})$. The organic layers were combined and washed with brine, dried over anhydrous $\mathrm{MgSO}_{4}$, filtered and concentrated. Mixture composition was analyzed by ${ }^{1} \mathrm{H}$ NMR.

Transvinylation reactions using chloro(1,5-cyclooctadiene)iridium(I) dimer catalyst. Isophthalic acid (1.66 g, $0.01 \mathrm{~mol}, 1$ eq.), vinyl acetate ( $8.6 \mathrm{~g}, 0.1 \mathrm{~mol}, 10 \mathrm{eq}$.$) , and chloro(1,5-$ cyclooctadiene)iridium(I) dimer $\left(0.335 \mathrm{~g}, 5 \cdot 10^{-4} \mathrm{~mol}, 0.05\right.$ eq. $)$ were dissolved in DMF. The reaction mixture was stirred for $24 \mathrm{~h}$ at $100{ }^{\circ} \mathrm{C}$ under $\mathrm{N}_{2}$. The reaction mixture was poured into water and the aqueous layer was extracted four times with dichloromethane. The organic layers were combined and washed with brine, dried over anhydrous $\mathrm{MgSO}_{4}$, filtered and concentrated. Mixture composition was analyzed by ${ }^{1} \mathrm{H}$ NMR.

\section{Preparative experiments on isophthalic and dodecanedioic acids}

Preparative transvinylation reaction from isophthalic acid with $[p y r i d i n e]_{2} \cdot \operatorname{Pd}(\mathrm{OAc})_{2}$ catalyst under conventional heating using the one-shot catalyst addition methodology.

Isophthalic acid $(16.6 \mathrm{~g}, 0.1 \mathrm{~mol})$, vinyl acetate $(86.0 \mathrm{~g}, 1.0 \mathrm{~mol}), p$-toluene sulfonic acid $(1.72 \mathrm{~g}$, $0.01 \mathrm{~mol})$ and [pyridine $]_{2} \cdot \operatorname{Pd}(\mathrm{OAc})_{2}\left(2.55 \mathrm{~g}, 5 \cdot 10^{-3} \mathrm{~mol}\right)$ were dissolved in anhydrous DMF (100 
$\mathrm{mL}$ ). The mixture was stirred and heated at $60{ }^{\circ} \mathrm{C}$ under $\mathrm{N}_{2}$ flow for $48 \mathrm{~h}$. Reaction was stopped by adding $\mathrm{CH}_{3} \mathrm{COOK}(0.98 \mathrm{~g}, 0.01 \mathrm{~mol})$ and water $(100 \mathrm{~mL})$. Diethyl ether $(50 \mathrm{~mL})$ was then added and the mixture triturated to allow precipitation of traces of unreacted isophthalic acid. The aqueous layer was extracted with dichloromethane $(4 \times 50 \mathrm{~mL})$. The organic layers were combined and washed with brine, dried over anhydrous $\mathrm{MgSO}_{4}$, filtered and concentrated. Reaction products were separated by bulb-to-bulb distillation under vacuum: divinyl isophthalate: $E b_{0.1}=130{ }^{\circ} \mathrm{C}$, (lit. $\left[{ }^{22}\right]: E b_{0.1}=120-125^{\circ} \mathrm{C}$ ), (oil, $6.5 \mathrm{~g}, Y=30 \%$ ); monovinyl isophthalate $E b_{0.1}=145-150{ }^{\circ} \mathrm{C}$, (oil, $11.5 \mathrm{~g}, Y=60 \%$ ).

Preparative microwave-assisted transvinylation reaction from dodecanedioic acid with $\operatorname{Pd}(\mathrm{OAc})_{2}$ catalyst using the successive catalyst addition methodology

First run. Dodecanedioic acid (23 g, $0.1 \mathrm{~mol})$, vinyl acetate $(86.0 \mathrm{~g}, 1.0 \mathrm{~mol}), p$-toluene sulfonic acid $(1.72 \mathrm{~g}, 0.01 \mathrm{~mol})$ and $\mathrm{Pd}(\mathrm{OAc})_{2}\left(1.12 \mathrm{~g}, 5 \cdot 10^{-3} \mathrm{~mol}\right)$ were dissolved in anhydrous DMF $(100 \mathrm{~mL})$. The reaction mixture was stirred in a microwave reactor for $2 \mathrm{~h}$ at $60{ }^{\circ} \mathrm{C}$. Reaction was stopped by adding $\mathrm{CH}_{3} \mathrm{COOK}(0.98 \mathrm{~g}, 0.01 \mathrm{~mol})$ and water $(100 \mathrm{~mL})$. Diethyl ether (200 $\mathrm{mL}$ ) was then added and the mixture triturated to allow precipitation of traces of unreacted dodecanedioic acid. The aqueous layer was extracted with dichloromethane $(4 \times 50 \mathrm{~mL})$. The organic layers were combined and washed with brine, dried over anhydrous $\mathrm{MgSO}_{4}$, filtered and concentrated. Mixture composition was analyzed by ${ }^{1} \mathrm{H}$ NMR. Further runs. The concentrate collected from the previous run was added with a mixture of fresh vinyl acetate $(86.0 \mathrm{~g}, 1.0 \mathrm{~mol}), p$-toluene sulfonic acid $(1.72 \mathrm{~g}, 0.01 \mathrm{~mol})$ and $\mathrm{Pd}(\mathrm{OAc})_{2}$ $\left(1.12 \mathrm{~g}, 5.10^{-3} \mathrm{~mol}\right)$ dissolved in anhydrous DMF $(200 \mathrm{~mL})$. Reactions and work-up were as for first run. Mixture composition was analyzed by ${ }^{1} \mathrm{H}$ NMR. The final crude mixtures were purified by silica gel column chromatography [Cyclohexane/Ethyl Acetate $(98: 2)$ ] and obtained as an oil, 18.3g, Yield $65 \%$.

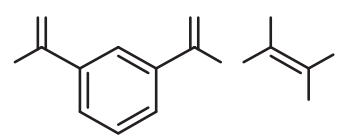

Monovinyl isophthalate. White solid, $\mathrm{mp} 140{ }^{\circ} \mathrm{C}$ (lit. ${ }^{14} \mathrm{mp} 145{ }^{\circ} \mathrm{C}$ ). UV: $\lambda_{\max }(\mathrm{EtOH}): 278 \mathrm{~nm}$. ${ }^{1} \mathrm{H}$ NMR (300 MHz, $\left.\mathrm{CD}_{3} \mathrm{OD}, \delta \mathrm{ppm}\right): 8.74\left(1 \mathrm{H}, \mathrm{m}, \mathrm{H}_{1}\right), 8.34-8.37\left(2 \mathrm{H}, \mathrm{m}, \mathrm{H}_{3,5}\right), 7.77(1 \mathrm{H}, \mathrm{m}$, $\left.\mathrm{H}_{4}\right), 7.75\left(1 \mathrm{H}, \mathrm{dd}, J 6 \mathrm{~Hz}\right.$ and $\left.J 15 \mathrm{~Hz}, \mathrm{H}_{9}\right), 5.15-5.22\left(1 \mathrm{H}, \mathrm{m}, \mathrm{H}_{12}\right), 4.81-4.84\left(1 \mathrm{H}, \mathrm{m}, \mathrm{H}_{11}\right) .{ }^{13} \mathrm{C}$ (75 MHz, $\mathrm{CD}_{3} \mathrm{OD}, \delta$ ppm): 205.28, 141.38, 134.63, 130.71, 129.64, 98.38.

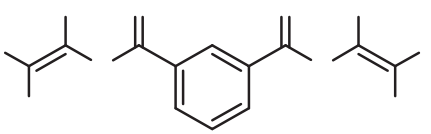


Divinyl isophthalate. White solid, mp $65^{\circ} \mathrm{C}$; $\left(\right.$ lit. $\left.{ }^{14} \mathrm{mp} \mathrm{59-60}{ }^{\circ} \mathrm{C}\right) . \mathrm{UV}: \lambda_{\max }(\mathrm{EtOH}): 260 \mathrm{~nm} .{ }^{1} \mathrm{H}$ NMR $\left(300 \mathrm{MHz}, \mathrm{CDCl}_{3}, \delta \mathrm{ppm}\right): 8.85\left(1 \mathrm{H}, \mathrm{m}, \mathrm{H}_{1}\right), 8.36-8.39\left(2 \mathrm{H}, \mathrm{m}, \mathrm{H}_{3,5}\right), 7.65(1 \mathrm{H}, \mathrm{t}, J 6 \mathrm{~Hz}$, $\left.\mathrm{H}_{4}\right), 7.53-7.60\left(2 \mathrm{H}, \mathrm{dd}, J 6 \mathrm{~Hz}\right.$ and $\left.J 15 \mathrm{~Hz}, \mathrm{H}_{9,9^{\prime}}\right), 5.16-5.21\left(2 \mathrm{H}, \mathrm{dd}, J 3 \mathrm{~Hz}\right.$ and $\left.J 12 \mathrm{~Hz} \mathrm{H}_{12,12^{\prime}}\right)$, 4.79-4.82 (2H, dd, $J 3 \mathrm{~Hz}$ and $\left.J 9 \mathrm{~Hz}, \mathrm{H}_{11,11}\right) .{ }^{13} \mathrm{C}\left(75 \mathrm{MHz}, \mathrm{CDCl}_{3}, \delta \mathrm{ppm}\right): 162.71,141.26$, $134.78,131.45,129.67,129.03,123.25,98.93$.<smiles>C=C(CC=C(C)C)CCCCCCCCCCCC(=C)CC=C(C)C</smiles>

Divinyl dodecanedioate. Liquid, ${ }^{1} \mathrm{H}$ NMR $\left(300 \mathrm{MHz}, \mathrm{CD}_{3} \mathrm{OD}, \delta \mathrm{ppm}\right): 7.26-7.33(2 \mathrm{H}, \mathrm{dd}, J 6$ $\mathrm{Hz}$ and $\left.J 15 \mathrm{~Hz}, \mathrm{H}_{2,2}\right), 4.85-4.90\left(2 \mathrm{H}, \mathrm{dd}, J 3 \mathrm{~Hz}\right.$ and $\left.J 6 \mathrm{~Hz}, \mathrm{H}_{5}, 5^{\prime}\right), 4.60-4.57(2 \mathrm{H}$, dd, $J 3 \mathrm{~Hz}$ and $\left.J 6 \mathrm{~Hz}, \mathrm{H}_{4,4^{\prime}}\right), 2.41\left(4 \mathrm{H}, \mathrm{t}, J 6 \mathrm{~Hz}, \mathrm{H}_{6,6^{\prime}}\right), 1.59-1.70\left(4 \mathrm{H}, \mathrm{m}, \mathrm{H}_{7,7}\right), 1.34-1.39\left(12 \mathrm{H}, \mathrm{m}, \mathrm{H}_{8,8}, 9\right.$ $\left., 9^{9}, 10,10^{\prime}\right) .{ }^{13} \mathrm{C}\left(75 \mathrm{MHz}, \mathrm{CD}_{3} \mathrm{OD} \delta \mathrm{ppm}\right): 25.80,30.20,30.37,30.44,34.70,97.89,142.53,172.28$.

\section{Acknowledgements}

This work was partly funded by the French National Research Agency (ANR) through a grant (HIPERM) to IB.

\section{References}

1. Faber, K.; Riva, F. Synthesis 1992, 895. http://dx.doi.org/10.1055/s-1992-26255

2. Uyama, H.; Kobayashi, S. Adv. Polym. Sci. 2006, 194, 133. http://dx.doi.org/10.1007/12_031

3. Husar. B.; Heller, C.; Schwentenwein, M.; Mautner, A.; Varga, F.; Koch, T.; Stampfl, J.; Liska, R. J. Polym. Sci. Part A. Polym. Chem. 2011, 49, 4927. http://dx.doi.org/10.1002/pola.24933

4. Murray, R. E.; Lincoln, D. M. Catal. Today 1992, 13, 92. http://dx.doi.org/10.1016/0920-5861(92)80189-T

5. Heller, C.; Schwentenwein, M.; Russmueller, G.; Varga, F.; Stampfl, J.; Liska, R. J. Polym. Sci. Part A Polym. Chem. 2009, 47, 6941. http://dx.doi.org/10.1002/pola.23734

6. Waller, F. J. In: Kosak, J. R.; Johnson, T. A. Eds. Catalysis of Organic Reactions, M. Dekker: NY 1994, p 397.

7. Swern, D.; Jordan, E. F. Jr. Org. Synth. Coll. 1963, 4, 977. http://dx.doi.org/10.15227/orgsyn.030.0106 
8. Bernhoft, R.; A. J. Env. Pub. Health 2012, 13, 1. http://dx.doi.org/10.1155/2012/460508

9. http://www.mercuryconvention.org/

10. Sabel, A.; Smidt, J.; Jira, R.; Prigge, H. Chem. Ber. 1969, 102, 2939. http://dx.doi.org/10.1002/cber.19691020908

11. Rashidi-Ranjbar, P.; Piri, F. Molecules 1999, 4, 135. http://dx.doi.org/10.3390/40500135

12. Ziriakus, J.; Zimmermann, T. K.; Pothig, A.; Drees, M.; Haslinger, S.; Jantke, D.; Kuhn, F. E. Adv. Synth. Catal. 2013, 355, 2845. http://dx.doi.org/10.1002/adsc.201300447

13. Nakagawa, H.; Okimoto, Y.; Sakaguchi, S.; Ishii, Y. Tetrahedron Lett. 2003, 44, 103. http://dx.doi.org/10.1016/S0040-4039(02)02451-6

14. Leadbeater, N. E. In Knochel, P.; Molander, G. A. Eds. Comprehensive Organic Synthesis $2^{\text {nd }}$ Ed, 2014, Vol. 9, p 234.

15. Nick, F.; Azna, R.; Sainz, D.; Muller, G.; Demoncau, A. Eur. J. Org. Chem. 2009, 29, 5020. http://dx.doi.org/ 10.1002/ejoc.200900697

16. Lee, C. K. Y.; Holmes, A. B.; Ley, S. V.; McConvey, I. F.; Al-Duri, B.; Leeke, G. A.; Santos, R. C. D.; Seville, J. P. K. Chem. Commun. 2005, 40, 2175. http://dx.doi.org/10.1039/B418669A

17. Ketterling, A. A.; Lisitsyn, A. S.; Nosov, A. V.; Likholobov, V. A. Appl. Cat. 1990, 66, 123. http://dx.doi.org/10.1016/S0166-9834(00)81632-2

18. Szabo, Z. G. In: Bamford, C. H. Ed. Comprehensive Chemical Kinetics. Elsevier Amsterdam, 1969, Vol. 2 p 1.

http://dx.doi.org/10.1016/B978-0-444-40674-3.50007-9

19. Kamble, S. P.; Manjarekar, O.; Mawale, R.; Kulkarni, B. D.; Chowdary, N.; Gupte, M. Y.; Barve, P. P. Int. J. Chem. Kinet. 2012, 44, 624. http://dx.doi.org/10.1002/kin.20704

20. Magrone, P.; Cavallo, F.; Panzeri, W.; Passarella, D.; Riva, S. Org. Biomol. Chem., 2010, 8, 5583.

http://dx.doi.org/10.1039/C0OB00304B

21. Stephenson, T. A.; Morehouse, S. M.; Powell, R.; Heffer, J. P.; Wilkinson, G. J. Chem. Soc. $1965,3632$. http://dx.doi.org/10.1039/JR9650003632

22. Hopff, H.; Lussi, H. Makromol. Chem. 1956, 18/19, 227. http://dx.doi.org/10.1002/macp.1956.020180121 